\title{
The Romance Advantage — The Significance of the Romance Languages as a Pathway to Multilingualism
}

\author{
Kathleen Stein-Smith \\ Fairleigh Dickinson University, Metropolitan Campus, Teaneck, NJ, USA
}

\begin{abstract}
As 41M in the US speak a Romance language in the home, it is necessary to personally and professionally empower L1 speakers of a Romance language through acquisition of one or more additional Romance languages. The challenge is that Romance language speakers, parents, and communities may be unaware of both the advantages of bilingual and multilingual skills and also of the relative ease in developing proficiency, and even fluency, in a second or third closely related language. In order for students to maximize their Romance language skills, it is essential for parents, educators, and other language stakeholders to work together to increase awareness, to develop curriculum, and to provide teacher training -- especially for Spanish-speakers, who form the vast majority of L1 Romance language speakers in the US, to learn additional Romance languages.
\end{abstract}

Index Terms - romance languages, bilingual education, multilingualism, foreign language learning, romance advantage

\section{INTRODUCTION}

The Romance languages, generally considered to be French, Spanish, Italian, Portuguese, and Romanian, and in addition, regional languages including Occitan and Catalan, developed from Latin over a significant period of time and across a considerable geographic area. The beginnings of the Romance languages can be traced to the disappearance of the Roman Empire, along with Latin, its lingua franca. Today they are spoken by over a billion native, or L1, speakers around the world (Ethnologue), and over 41M in the US (Ryan, 2013).

Yet although significant differences exist among the modern languages today, mutual intelligibility and lexical similarities not only make understanding across languages possible, to varying degrees, but perhaps more importantly, in the globalized and interconnected world, they also facilitate learning additional Romance languages for the L1 and L2 speaker/learner alike.

While there are a number of course offerings designed for Romance language speakers intending to learn an additional Romance language, the impact of building on the commonalities among closely related languages in order to build bilingualism, and even multilingualism, is not always part of the general conversation in the US. The term intercomprehension has been used, generally in Europe, to describe the connections and possibilities among closely related languages and their cultures (APIC; Nadeau \& Barlow, 2012; EC).

Encouraging Romance language speakers, heritage language speakers, and proficient learners, to study an additional Romance language, and using intercomprehension and other strategies that maximize the similarities between languages, would be an effective strategy to increase language skills and cultural knowledge. It would also be an effective advocacy strategy to increase interest in the less studied Romance languages, which include Portuguese, an increasingly important language in international business and communication.

\section{The Romance Languages at a Glance}

In addition to being an official language of Spain and throughout South America, Central America, Mexico, and in the Caribbean, Spanish is the language most frequently spoken in the home after English in the US. With over 400M native speakers, primarily in Spain and Latin America, Spanish is an international language and has the second largest number of native speakers in the world, second only to Mandarin Chinese (Ethnologue). In addition, Spanish is spoken in the home by $41 \mathrm{M}$ in the US, making it the second most widely spoken language in the US. It is also the most widely studied foreign language in the US (ACTFL; MLA, 2015).

French is spoken throughout the world, with 80 members in the Organisation internationale de la Francophonie, and is the third most spoken language in the US -- the most frequently spoken language after English in 4 states, and the most frequently spoken after English and Spanish in 11 states altogether (Blatt, 2014). In addition, Canada, which shares the longest border with the US is officially bilingual in English and French. With over 200M first language speakers around the world, French is a global language, spoken on every continent (Ethnologue). After English, it is the second most widely studied foreign language in the world (OIF, 2014), and is the second most widely studied language 
in the US. In addition, French is considered the third most useful language for international business (English, Chinese, and French, 2011). Over 2M speak French in the US (Ryan, 2013). It is interesting to note that French is also the language of medicine in the US, as the most frequent language of doctors after English and Spanish in 16 states (Jones).

In the US, Spanish is the most frequently spoken language after English in 43 states. French is the most frequently spoken language after English in 4 states, leaving only 3 of our 50 states in which a Romance language is not the most frequently spoken language after English (Blatt, 2014).

In addition to French and Spanish, Portuguese and Italian are important languages both globally and within the United States. Portuguese is spoken by over well 200M native speakers, primarily in Brazil, Portugal, and Africa (Ethnologue), and by nearly 700K in the US (Ryan, 2013). However, it is interesting to note that it is considered to be among the Less Commonly Taught Languages (LCTLs) in the US. Italian is spoken by 65M native speakers, primarily in Italy (Ehnologue), and by over $700 \mathrm{~K}$ in the US (Ryan, 2013). It is among the most frequently studied languages in the US. Romanian is spoken by another 25M native speakers, primarily in Romania (Ethnologue).

According to the Census, over 60M Americans speak a language other than English in the home, and of this 60M, over $41 \mathrm{M}$ are speaking a Romance language, with French and Spanish the two Romance languages most frequently spoken. In terms of all languages other than English spoken in the US, Spanish is the most frequently spoken after English, and French/French Creole is the third most frequently spoken (Ryan, 2013).

French is the second most widely studied language in the world -- second only to English, with over $125 \mathrm{M}$ learners around the world (OIF, 2014). In the US, Spanish and French are the most widely studied languages. At the college and university level, 3 of the top 5 languages studied are Romance languages, Spanish, French, and Italian. Italian is the fourth most studied language in the world (Edwards, 2016). Latin is among the top 10, and Portuguese showed an increase of over $10 \%$ between 2009 and 2013, one of only 3 languages to show an percentage increase (MLA, 2015; U.S. Demand). At the K-12 level, Spanish and French are also the most frequently studied languages, with $7.4 \mathrm{M}$ and 1.3M enrolled respectively, and Latin is included among the major languages (ACTFL).

It is interesting to note that external advocates, including foreign governments, advocate for their national language and culture worldwide. Among Romance language organizations, these include the Institut Français and Alliance Française, the Società Dante Alighieri, and the Instituto Camões, and the Instituto Cervantes, intended to promote worldwide French, Italian, and Portuguese, and Spanish language and culture respectively. Recently, French President Macron has spoken of the global role of French, saying that French would be "the first language of Africa, and perhaps of the world" (Smith, 2017).

\section{The Cultural And Political Influence of the Romance LANGuages}

The Romance languages have cultural, political, and economic significance, both around the world and in the US. Language also includes economic and cultural dimensions, and the global economic and cultural influence of the Romance languages is considerable. The Francophonie generates 8\% of global GDP (OIF, 2014), while France, Italy, Brazil, and Canada are among the top 10 largest economies in the world (WEF, 2017). In terms of cultural influence, the Romance languages have played a significant role, with Spanish, French, and Portuguese demonstrating historical and cultural influence of Spain, France, and Portugual across the globe, and the historical and cultural influence of Italy, home of the Roman Empire and considered by many to be the birthplace of the Renaissance. In terms of global image, France ranks second in the world in a recent survey, with Canada, Italy, and Switzerland also in the top 10 (Why France, 2017). In terms of "soft power," France ranks first in the world, with Canada and Switzerland, also French-language nations, also in the top 10 (Gray, 2017).

Romance languages are widely spoken around the world, and the top five most widely spoken Romance languages alone account for approximately 1B native speakers, and 300M additional second language speakers (Ethnologue). In the US, more than 41M -- or one in seven -- Americans speak a Romance language in the home (Ryan, 2013). French and Spanish are the most widely studied foreign languages in the US (ACTFL; MLA, 2015), and French is the second most widely studied language in the world (OIF, 2014).

Beyond the languages themselves, the impact of the Romance-speaking world, which has spread well beyond Europe, is a factor in our collective culture and heritage, past and present, and in global politics, economics, and business. Understanding additional Romance languages opens the door to increased intercultural understanding.

In addition to their importance today, both in the US and around the world, the Romance languages have historical significance. Along with English -- French, Spanish, and Portuguese were languages of colonization around the world, and historically, large parts of what is now the US were once part of the French or Spanish colonial empire in North America, clearly visible still today through place names like Saint Louis, San Francisco, and many more. Italian is the modern language of what was once the center of the Roman Empire.

In terms of influence, it is interesting to note that, of the six official languages of the UN, two -- French and Spanish - are Romance languages, while the remaining represent diverse language families. Two of the ten languages with the most native speakers -- Spanish and Portuguese -- are Romance languages (Ethnologue). Three of the top ten most powerful languages in the world -- French, Spanish, and Portuguese -- are Romance languages (WEF). France is considered the world leader in "soft power" (Gray, 2017). 
This combination of cultural, historical, political, and economic significance, the large number of native L1 speakers and Romance language L2 learners around the world and in the US, as well as the degree of mutual intelligibility and lexical similarity among them, make it essential for foreign language educators to encourage study of additional Romance languages by both native speakers and proficient/advanced learners.

Romance languages are among the most widely studied in the US, with Spanish and French the most studied foreign languages in K-12 and at the college and university level. Italian and Portuguese have smaller enrollments, but interest in both has increased in recent years, due to demand from students with Spanish or Portuguese ancestry, the worldwide importance of the cultures, and in the case of Portuguese, due to the increasing economic and geopolitical importance of Brazil. Spanish, French, and Italian are among the most frequently studied languages in the US at both the K-12 and college and university level (MLA, 2015). In addition, Latin remains the official language of the Roman Catholic Church.

Esperanto, perhaps the most famous constructed auxiliary language, draws its vocabulary largely from the Romance languages. It has approximately 2M speakers, 1,000 to 2,000 may be considered native speakers.

\section{The ECONOMic Significance of The Romance LANGuAges}

In addition to the historical and cultural significance of the Romance languages, it is also important to consider the economic significance of the Romance languages within the context of a globalized world.

In terms of economic impact, it is interesting to note that, according to Bloomberg, four of the top ten most useful languages for international business -- French, Spanish, Portuguese, and Italian -- are Romance languages (English, Chinese, and French, 2011). Four of the top 10 nations in the world ranked by GDP are Romance language-speaking countries - France, Brazil, Italy, and Canada (Statistics Times). 79 of the Global Fortune 500 are in Romance languagespeaking countries, with France leading the group with 29 Global Fortune 500 companies (Global Fortune 500).

Former colonies of Spain have a combined GDP of \$3.56T, or 4\% of the world total, plus an additional \$1.35T for Spain. Former colonies of France have a combined GDP of \$822.63B, plus an additional \$2.61T for France alone. Brazil, a former colony of Portugal has a GDP of \$2.25T (11 times that of Portugal). The GDPs of Italy, Portugal, and Romania are $\$ 2.01 \mathrm{~T}, \$ 212.45 \mathrm{~B}$, and $\$ 169.40 \mathrm{~B}$ respectively. This totals almost 13T GDP, demonstrating the economic status of the Romance language world. (NationMaster).

In a study of the economic return on foreign language study, estimated to be at around $2 \%$ of lifetime earnings (Johnson, 2014), not only were French and Spanish among the top three, but if proficiency could be achieved in more than one of the closely-related Romance languages, the return on investment (ROI) would be even more considerable.

In terms of cultural significance, of Nobel Prize Prize winners in literature, 16 are from France, the largest number from any single country, and of these Nobel Prize laureates, 36 wrote in Romance languages, a total of $32 \%$ of the 114 winners 1901-2017 (List of Nobel Laureates). 4 of the top 10 countries in terms of the number of books published per year in the world - France, Brazil, Spain, and Italy - are Romance language countries (Ha, 2017). In terms of internet use, 3 of the top 10 languages of internet users, and 4 of the top 10 languages of internet content, are Romance languages (Languages Used).

12 of the top 100 universities in the world are located in Romance language-speaking countries (QS, 2018), and 3 of the top 5 most visited tourist destinations in the world are Romance language-speaking countries - France, Spain, and Italy (World Tourism).

\section{The Romance Advantage as a Pathway to Multilingualism}

The shared history and current similarities among the Romance languages point toward the effective use of the Romance advantage in maximizing learning of additional Romance languages by both L1 and, to some extent, L2 speakers, whether through intercomprehension -- understanding of a second language through its similarity to the mother tongue of the reader or listener, or through specific teaching methods and materials, as well as learning strategies, including cognate recognition strategies, to maximize learning of additional languages. The conversation among proponents of developing proficiency and even fluency across the Romance languages has even gone so far as to include a discussion of whether additional languages should be learned sequentially or simultaneously (McCann, Klein, \& Stegmann, 2002).

The key advantage of foreign language study within the Romance language group, or within another group of closely-related languages, is that generally the time and effort required to achieve proficiency and fluency are significantly less than those required for a beginner without prior knowledge of a Romance language.

While French, Spanish, Italian, Portuguese, and Romanian are different languages today, they are all descended from Latin, the language of Rome and the Roman Empire, the global language of the pax romana. Even English, a Germanic language, was influenced by Norman French, and much of our vocabulary is of French and/or Latin Romance origin.

Speakers of one Romance language can understand each other to varying degrees and can more easily learn additional romance languages than those who speak less closely related languages. Mutual intelligibility (Cinobanu \& Dinu, 2014), lexical similarity, and linguistic distance are among the terms used to describe the dynamic relationship among closely related languages. 
In Europe, the term intercomprehension has been used to describe mutual intelligibility in terms of second language learning within the context of plurilingualism, with learning one language no longer an end in itself, but rather the means to develop multilingual and intercultural skills (APIC; Gooskens et al, 2018). The goal of intercomprehension is to understand the target language based on knowledge of your own closely-related language, and stems from the European concept of plurilingualism based on its core value of multilingualism. However, the limits of intercomprehension in terms of understanding are not yet clear.

The Romance advantage, on the other hand, takes advantage of and builds upon the linguistic knowledge of the learner in order to actually learn the additional language(s). This advantage for native speakers, or those proficient in a Romance language, in the learning of additional Romance languages could even be considered a Romance "bonus," or "discount," in terms of the percentage of the new language that comes easily, or almost effortlessly, due to previous knowledge of another Romance language. It is also possible that even non-native speakers of Spanish or another Romance language, depending on their level of proficiency, may experience at least some of the benefits of building on their knowledge in learning an additional Romance language in written, and also in spoken, forms.

While there are those who would bring back Latin as the global lingua franca, or expand the learning and use of Esperanto, students today would benefit from learning at least one modern Romance language, and those who are firstlanguage or heritage speakers of one of those would benefit from achieving business proficiency or fluency, and both groups would benefit from leveraging their existing skills to include one or more additional Romance languages.

Although the idea of learning multiple Romance languages at the same time is not a new one, even though language departments in colleges and universities are often called Romance language departments, there is often little effort made to teach languages together, in a comparative and contrastive manner, but rather they are generally taught separately. The classic A Comparative Practical Grammar of French, Spanish and Italian, (Heatwole \& Pei, 1976) is an example of using the Romance advantage as a pathway to multilingualism. The potential benefit of study of Latin, and even of Esperanto, in the learning of the Romance languages has often been discussed. In the case of Latin, while approximately $90 \%$ of vocabulary in the Romance languages is ultimately of Latin origin, the Romance languages evolved - over a considerable time period and across a significant geographic expanse - only indirectly from the classical Latin typically taught in school, but more directly from spoken Latin, often referred to as vulgar Latin, as it evolved locally across what had been the Roman Empire. While Latin is linked to many academic benefits, and may serve to increase general linguistic awareness, the modern Romance languages are - to varying degrees - quite different from Latin. The potential benefit of beginning foreign language study, or study of the Romance languages, with Esperanto tends to center more on the development of the habits of mind needed by the foreign language learner new to Romance languages or by the new foreign language learner The Romance advantage can be a pathway to both foreign language skill, greater intercultural understanding, and career success. Initiatives to maximize the Romance advantage can easily be found in Europe and the US, including courses at the University of Washington, MIT, the University of Southern California, the University of Arizona, and a workshop at California State Long Beach. In Europe, there has been research, as well as similar initiatives, including the European Awareness and Intercomprehension Project and Eurocomprehension in Romance Languages (EuroComRom) (Byram \& Hu, 2013), as well as numerous initiatives by the Institut Français. French also has une place spéciale in the Romanian educational system (Government of Romania). In learning a second or third Romance language, learners build on existing knowledge and intuitive skills, emphasizing how specific Romance languages are alike and, importantly, how they differ, with a quick start, a targeted approach, and maintaining momentum key to success. Reading parallel texts, either within a textbook or curriculum, or through an organization that routinely produces texts in a variety of languages can also be helpful in developing confidence and in becoming accustomed to both similarities of the starting language and the target language (Lunn, 2017). If we look at Latin and the Romance languages within the context of language change, it is interesting to note that English, while not a Romance language or descended directly from Latin, has many Latin and Romance elements in its vocabulary, stemming from the historical influence of Norman French on Anglo Saxon during the period following the Norman Conquest, and also stemming from the many scientific and technical terms inspired directly by Latin, as needed. An example of the effectiveness of the Romance advantage as a pathway to multilingualism would be the success of Romance language speakers from around the world as French and Spanish language winners in the Many Languages One World Essay Contest and Global Youth Forum. (MLOW). MLOW is a contest in which college and university from around the world are invited to submit an essay -- in a learned second language, also one of the official languages of the United Nations -- on an assigned topic related to the principles of the UN Academic Impact (2014), and the Sustainable Development Goals (SDGs), beginning in 2015. Finalists are interviewed via Skype in the learned second language, and winners are brought New York where they spent several days on a US college campus, working in transnational teams on a group presentation, always in the learned second language, in the United Nations General Assembly Hall. Many of the French and Spanish winners have been native speakers of another Romance language and fluent speakers of one or more additional Romance languages. For example, many of the French language winners have been L1 speakers of a Romance language, from Brazil, Mexico, Peru, Romania, and Spain, among many other countries. In order to empower native and heritage speakers, as well as proficient Romance language learners, it is necessary to facilitate learning additional Romance languages through courses specifically designed to build bridges directly from one Romance language to another, without the unnecessary distraction of English as the language of departure and as 
part to the process, and to teach additional Romance languages in the spirit of cross-training. The cross-training metaphor is especially applicable in describing the Romance advantage. The regular use of another language has been demonstrated to support mental acuity and to delay the onset of dementia. As the use of one or more additional languages is beneficial to our mental fitness, using the Romance advantage to facilitate learning of more than one Romance language is akin to cross-training, which uses several types of exercise to increase fitness. While the learning and use of more than one language can be considered a form of linguistic cross-training, the additional factor to consider here is that learning an additional Romance language becomes easier with each one learned, the Romance "discount" increasing with each Romance language learned. Courses intended for Romance language speakers learning an additional Romance language already exist, primarily offering French, Portuguese, and Italian for Spanish-language speakers, in institutions around the country, and provide a model for future growth. Teaching methods and materials need to be expanded to maximize the connections between languages, and the Romance advantage. (Carvalho et al., 2010) recommend the use of authentic materials and highlighting of differences between L1 and L2, in this case, Portuguese for Spanish speakers. Although the Romance advantage is the most significant and applicable in the US, it is also necessary to add that a parallel advantage exists for language learners within other closely related language families, including the Germanic and Slavic languages, which are part of the conversation on intercomprehension within the EU.

\section{Romance Language AdVocacy}

In order for more students to benefit from the Romance advantage, parents, communities, and -- most importantly -students and prospective students need to become more aware of both the personal and professional benefits of learning an additional Romance language, and the extent to which that process is facilitated by knowledge of a first Romance language, which in the US, is predominantly Spanish. Once motivation has been created, teacher training and development of specific curriculum and materials to support learning of French, Italian, and Portuguese by Spanishspeakers and by proficient L2 speakers of Spanish. Additional language combinations would follow.

Advocacy, defined as the "act or process of supporting a cause or proposal," by Merriam-Webster, is essential to motivate students to begin foreign language study and to continue foreign language to proficiency and/or fluency. Romance language advocacy, a subset of foreign language advocacy, includes many of the same elements as all foreign language advocacy. However, foreign language advocacy is often either limited to a particular language, or encompasses foreign language learning overall, within the context of professional associations of foreign language educators and other language stakeholders.

What is needed is very specific advocacy to increase awareness of the importance of the Romance language-speaking world to which enhanced access is possible through language skills and more in-depth knowledge of the culture. Once interest and motivation exist, information on the real benefits of the Romance advantage need to be made known to students, parents, and communities, as well as specific information on accelerated pathways to proficiency.

It is important for foreign language educators to reflect on the fact that although teaching additional Romance languages directly to Romance language speakers may seem to break down traditional barriers among teachers of one or more specific languages, it actually builds bridges between foreign languages and between foreign language educators. It also offers not only a pathway to trilingualism, but is in alignment with the goals of "translingual and transcultural competence " and strengthening "the demand for language competence within the university," as stated in the 2007 MLA report, Foreign Languages and Higher Education: New Structures for a Changed World (Carvalho, Luna Freire, and da Silva, 2010).

This is, however, not only a conversation about foreign languages, but it is about the future of students, and building support among parents and in local communities is key. Increasing awareness among students and potential students is important, but it is also important to obtain buy-in from parents and family members, who may not always be aware of the relatively shorter pathway to proficiency in a second Romance language and of the benefits that proficiency, and even fluency, in a second or third Romance language can bring. The development of career pathways, partnerships with business, local communities and other language stakeholders, and the development of experiential learning opportunities, as well as relevant recognitions and rewards are all beneficial is developing sustainable motivation.

Collaboration among the professional language education associations representing the Romance languages, bilingual and heritage language groups, along with parents and language enterprise partners is essential.

While this collaborative effort among parents, teachers, and communities may be challenging, the potential benefits to our students and to our society are significant. An early start, beneficial in all foreign language learning, could potentially empower Romance language learners to achieve fluency across all the major Romance languages, bringing the appreciation of all Romance culture as well as career advantages.

\section{FUTURE NEEDS}

With over 41M speaking a Romance language in the home in the US, while the US suffers from a foreign language deficit, it is essential to maximize the Romance advantage in order to empower Romance language speakers and heritage language speakers, as well as proficient Romance language learners, to use the lexical similarity and mutual 
intelligibility of the Romance languages to learn additional Romance languages and to develop translingual and transcultural competency.

More research is needed on how best to teach additional Romance languages to native, heritage, and proficient speakers through foreign languages courses, both in person and online, for all age groups, and through immersion programs designed to maximize the Romance advantage. Teacher training and development of curricular and support materials will also be needed.

It is also important to reflect on which language(s) to teach and learn. While mutual intelligibility and lexical similarity vary among the Romance languages, largely for historical and geographical reasons, they remain closely related. For that reason, the question as to which language to start with should largely be decided based on personal and professional interest.

It is also important to consider different designs for learning, and it is possible to envision intensive programs, including immersion and short-term, and accelerated programs, as well as online programs empowering Romance language speakers to acquire one or more additional Romance languages. The "bilingual revolution," bringing dual language immersion to students throughout the NYC area and beyond, is an excellent example of dual language immersion, and could serve as a model for Romance language immersion. Other initiatives worth further examination in terms of building bridges among Romance languages include the NYC Bilingual Fair, now also in San Francisco, and the Seal of Biliteracy.

The need is clear. With over 41M speaking a Romance language in the home in the US, it is essential to develop curriculum, programs, and materials, and to train teachers, to empower these students by maximizing the Romance advantage.

Moreover, as the vast majority of these US Romance language speakers are Spanish-language speakers, curriculum, immersion and traditional programs, and teachers are urgently needed to teach Portuguese, Italian, French and other Romance languages to Spanish-language speakers using methods and materials to maximize the Romance advantage.

The number of additional conversations and connections, as well as the opportunity to experience additional cultures directly, without need of a translator or interpreter, and the insights gained about our own language, culture, and history make learning another Romance language a bargain too good to resist.

\section{CONCLUSIONS}

The case for the Romance advantage is clear, with knowledge of one or more additional Romance languages offering a pathway to personal, cultural, and career advantage for learners of all ages. Trans-Romance teaching and learning needs to move from the niche to the mainstream in foreign language education.

The issue is that Romance language speakers may not be aware of the power of both intercomprehension (Donato) and of the Romance advantage in learning another language and in the benefits that knowledge of additional languages will bring them.

Increasing awareness of the relative ease of learning a closely related additional language, along with the benefits of bilingual skills both personally and professionally is an essential first step. It is essential for foreign language educators, advocates, and supporters work together to develop curriculum based on linguistic similarities and emphasizing the strategies that Romance language speakers can use to quickly develop skills in the target languages.

Internships and other experiential learning opportunities, and career pathways to encourage continued study of additional Romance languages and to develop the professional linguistic and cultural skills needed to maximize the Romance advantage as a career and professional advantage are essential next steps. Beyond the personal and professional benefits of knowledge of additional languages, and the role and importance of the Romance advantage in supporting and sustaining linguistic growth, it is necessary to think of the significance of linguistic skills and cultural knowledge in global citizenship. Numerous US initiatives, as well as those in the European Union offer examples of curriculum, and the Organisation internationale de la Francophonie offer examples of what can be achieved when a common language is used to support and expand shared values. It would be worthwhile to consider maximizing the shared linguistic, cultural, and historical heritage of Romance-speaking populations around the world through a similar initiative transcending any single language group and spanning the entire Romance-speaking world.

\section{REFERENCES}

[1] American Council on the Teaching of Foreign Languages. Foreign Language enrollments in K-12 public schools: Are students ready for a global society? https://www.actfl.org/news/reports/foreign-language-enrollments-k-12-public-schools-are-studentsready-global-society (accessed 21/5/18).

[2] American Councils for International Education. (2017). The National K-12 Foreign Language Enrollment Survey Report. https://www.americancouncils.org/flereport (accessed 21/5/18).

[3] Blatt, Ben (2014). Tagalog in California, Cherokee in Arkansas: What language does your state speak? http://www.slate.com/articles/arts/culturebox/2014/05/language_map_what_s_the_most_popular_language_in_your_state.html (accessed 21/5/18). 
[4] Brown, Jennifer. (2017). Macron's France has dethroned Trump's America as the world's top soft power https://qz.com/1033191/emmanuel-macrons-france-has-topped-the-global-soft-power-index-pushing-donald-trumps-us-tothird-place/ (accessed 21/5/18).

[5] Carvalho, A. M., Luna Freire, J., \& da Silva, A.J.B. (2010). "Teaching Portuguese to Spanish Speakers: A Case for Trilingualism." Hispania 93:1 (2010): 70-75.

[6] Ciobanu, Alina Maria, \& Dinu, Liviu P. (2014). On the Romance Languages Mutual Intelligibility. http://www.lrecconf.org/proceedings/lrec2014/pdf/1183_Paper.pdf (accessed 21/5/18).

[7] Consolato Generale d'Italia, Los Angeles. (2012). Teaching Italian to Spanish-speakers through Intercomprehension: new perspectives in Los Angeles. http://www.conslosangeles.esteri.it/consolato_losangeles/en/la_comunicazione/dal_consolato/2012/11/intercomprehention.html (accessed 21/5/18)

[8] Donato, Clorinda. The Ties that Bind: Italian for Spanish Speakers in Intercomprehension http://www.usspeaksitalian.org/tiesbind-italian-spanish-speakers-intercomprehension (accessed 21/5/18).

[9] Edwards, Catherine. (2016). Love, food, and music: Why Italian is now the world's fourth most studied language. https://www.thelocal.it/20161027/love-food-and-music-why-italian-is-now-the-worlds-fourth-most-studied-language (accessed 21/5/18).

[10] English, Chinese, French most useful for business. https://www.languagemagazine.com/english-chinese-french-most-usefulfor-business/ (accessed 21/5/18)

[11] Ethnologue: Languages of the world. https://www.ethnologue.com/ (accessed 21/5/18).

[12] European Commission. European Awareness and Intercomprehension. http://www.euintercomprehension.eu/index.html (accessed 21/5/18).

[13] Fortune Global 500. http://fortune.com/global500/list/ (accessed 21/5/18).

[14] La France en Italie. Enseigner le français. https://it.ambafrance.org/-Enseigner-le-francais- (accessed 21/5/18).

[15] French for Spanish Speakers. French for Spanish Speakers Courses at CSU Long Beach. http://ielanguages.com/blog/frenchfor-spanish-speakers/ (accessed 21/5/18).

[16] Gooskens, C., van Heuven, V.J., Golubovic, J., Schuppert, A., Swarte, F., \& Voigt, S. (2017). Mutual intelligibility between closely related languages in Europe. International Journal of Multilingualism 15:2 169-193.

[17] Government of Romania. Ministère des Affaires étrangères. L'enseignement en français, en Roumanie. http://www.mae.ro/fr/node/12456 (accessed 21/5/18).

[18] Gray, Alex (2017). The World's 10 Biggest Economies in 2017. https://www.weforum.org/agenda/2017/03/worlds-biggesteconomies-in-2017/ (accessed 21/5/18).

[19] Gray, Alex (2017). France becomes the world no 1 for soft power. https://www.weforum.org/agenda/2017/07/france-newworld-leader-in-soft-power/ (accessed 21/5/18).

[20] Ha, Thu Huong. (2017). China and the US make nearly half the world's books. https://qz.com/1057240/which-countrypublishes-the-most-books/ (accessed 21/5/18).

[21] Heatwole, O.W., and Pei, M.A. (1976). A Comparative practical grammar of French, Spanish, and Italian. NY: Vanni, 1976.

[22] Johnson: What is a foreign language worth? https://www.economist.com/blogs/prospero/2014/03/language-study (accessed 21/5/18).

[23] Jones, Meghan. This Is the Most Common Language Spoken by Doctors (Besides English and Spanish) https://www.rd.com/culture/most-common-languages-doctors/ (accessed 21/5/18).

[24] Languages Used on the Internet. https://en.wikipedia.org/wiki/Languages_used_on_the_Internet (accessed 21/5/18).

[25] L'Association pour la promotion de l'intercompréhension (APIC). htttp://apic.onlc.fr/3LINTERCOMPREHENSION.html (accessed 21/5/18)

[26] List of Nobel Laureates in Literature. https://en.wikipedia.org/wiki/List_of_Nobel_laureates_in_Literature (accessed 21/5/18).

[27] Lunn, Patricia V., and Alkhas, Anita Jon. (2017). Learning French from Spanish and Spanish from French: A Short Guide. Washington, DC: Georgetown UP.

[28] Many Languages One World. https://www.manylanguagesoneworld.org/ (accessed 21/5/18).

[29] Massachusetts Institute of Technology. Accelerated Introductory Portuguese for Spanish Speakers https://ocw.mit.edu/courses/global-studies-and-languages/21g-880-accelerated-introductory-portuguese-for-spanish-speakersfall-2013/ (accessed 21/5/18).

[30] McCann, W.J., Klein, H.G., and Stegman, T.D. (2002). The Seven Sieves: How to Read All the Romance Languages Right Away. Brussels: EuromCom/Shaker.

[31] Modern Language Association. (2015). Enrollments in Languages Other Than English in United States Institutions of Higher Education, Fall 2013 https://www.mla.org/content/download/31180/1452509/EMB_enrllmnts_nonEngl_2013.pdf (accessed 21/5/18).

[32] Nadeau B. \& Barlow, J. (2012). Intercomprehension: A New Way of Learning. http://nadeaubarlow.com/intercomprehensiona-new-way-of-learning/ (accessed 21/5/18).

[33] NationMaster. http://www.nationmaster.com/ (accessed 21/5/18).

[34] Organisation internationale de la Francophonie (2014). La Langue française dans le monde. https://www.francophonie.org/274millions-de-francophones-dans.html (accessed 21/5/18).

[35] Portuguese for Spanish Speakers. https://www.languagemagazine.com/portuguese-for-spanish-speakers/ (accessed 21/5/18).

[36] QS World University Rankings 2018 https://www.topuniversities.com/university-rankings/world-university-rankings/2018 (accessed 21/5/18).

[37] Ryan, Camille. (2013). Language Use in the United States. https://www.census.gov/prod/2013pubs/acs-22.pdf (accessed 21/5/18). 
[38] Smith, Lydia. (2017). Emmanuel Macron vows to make French the World's first language http://www.independent.co.uk/news/world/europe/emmanuel-macron-french-language-france-president-world-first-africaburkina-faso-a8084586.html (accessed 21/5/18).

[39] Statistics Times. (2018). List of Countries by Projected GDP. http://statisticstimes.com/economy/countries-by-projectedgdp.php (accessed 21/5/18).

[40] United States Census Bureau. (2015). Census Bureau reports at least 350 languages spoken in U.S. Homes. https://www.census.gov/newsroom/press-releases/2015/cb15-185.html (accessed 21/5/18).

[41] University of Arizona. Teaching Portuguese to Spanish-Speaking Learners http://cercll.arizona.edu/teaching-portuguese-tospanish-speaking-learners-2 (accessed 21/5/18).

[42] University of Southern California. Teaching French to Spanish Speakers. http://www-ccd.usc.edu/francophone-center/teachingfrench-to-spanish-speakers/ (accessed 21/5/18).

[43] University of Washington. Portuguese for Spanish Speakers. https://spanport.washington.edu/portuguese-spanish-speakers-0 (accessed 21/5/18).

[44] U.S. demand for Portuguese increasing. https://www.languagemagazine.com/u-s-demand-for-portuguese-increasing/ (accessed 21/5/18).

[45] Why France has a better global image than the UK and US. https://www.thelocal.fr/20171123/france-now-has-a-better-imagethan-the-uk-and-us (accessed 21/5/18).

[46] World Tourism Rankings. https://en.wikipedia.org/wiki/World_Tourism_rankings (accessed 21/5/18).

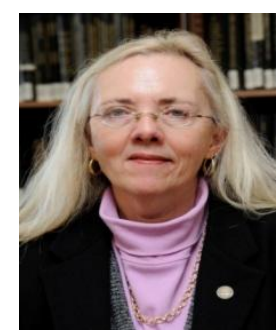

Kathleen Stein-Smith, $\mathrm{PhD}$, Chevalier dans l'Ordre des Palmes académiques, is associate university librarian and adjunct faculty in foreign languages and related areas at Fairleigh Dickinson UniversityMetropolitan Campus, Teaneck, New Jersey.

As a dedicated foreign language educator and advocate, she is Chair of the AATF (American Association of Teachers of French) Commission on Advocacy. She is a member of the ATA (American Translators Association) Education and Pedagogy Committee, the CSCTFL (Central States Conference on the Teaching of Foreign Languages) Advisory Council, the NECTFL (Northeast Conference on the Teaching of Foreign Languages) Advisory Council, and is a SCOLT (Southern Conference on Language Teaching) Sponsor. She also serves as French Language Facilitator at MLOW (Many Languages One World).

She has presented at numerous professional conferences, is the author of three books and numerous articles about the foreign language deficit, has given a TEDx talk, The U.S. Foreign Language Deficit_-What It Is; Why It Matters; and What We Can Do about It", and maintains a blog, "Language Matters." 